\title{
RETRACTED ARTICLE: Correlation between acoustic and other forms of energy emissions from fracture phenomena
}

Giuseppe Lacidogna • Oscar Borla •

Gianni Niccolini $\cdot$ Alberto Carpinteri

Received: 29 November 2013/Accepted: 19 May 2014/Published online: 1 July 2014

(C) Springer Science+Business Media Dordrecht 2014

This article has been withdrawn by the Publisher and the Society in agreement with the Editor-in-Chief due to conflict of interest reasons. In a commitment to scientific integrity we decided to withdraw the article as the editorial process had been compromised.

G. Lacidogna · O. Borla $(\bowtie) \cdot$ G. Niccolini .

A. Carpinteri

Department of Structural, Geotechnical and Building Engineering, Politecnico di Torino, Corso Duca degli Abruzzi 24, 10129 Turin, Italy

e-mail: oscar.borla@polito.it 